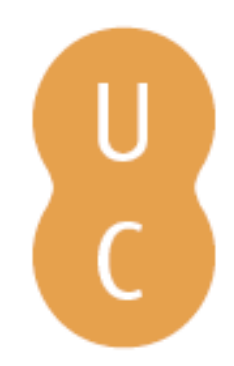

\title{
nombalina
}

Ruben A.: configurações de um mapa literário

Autor(es): $\quad$ Goulart, Rosa Maria

Publicado por: Imprensa da Universidade de Coimbra

URL

persistente: URI:http://hdl.handle.net/10316.2/38716

DOI: $\quad$ DOI:http://dx.doi.org/10.14195/978-989-26-1164-8_39

Accessed : $\quad$ 26-Apr-2023 16:02:59

A navegação consulta e descarregamento dos títulos inseridos nas Bibliotecas Digitais UC Digitalis, UC Pombalina e UC Impactum, pressupõem a aceitação plena e sem reservas dos Termos e Condições de Uso destas Bibliotecas Digitais, disponíveis em https://digitalis.uc.pt/pt-pt/termos.

Conforme exposto nos referidos Termos e Condições de Uso, o descarregamento de títulos de acesso restrito requer uma licença válida de autorização devendo o utilizador aceder ao(s) documento(s) a partir de um endereço de IP da instituição detentora da supramencionada licença.

Ao utilizador é apenas permitido o descarregamento para uso pessoal, pelo que o emprego do(s) título(s) descarregado(s) para outro fim, designadamente comercial, carece de autorização do respetivo autor ou editor da obra.

Na medida em que todas as obras da UC Digitalis se encontram protegidas pelo Código do Direito de Autor e Direitos Conexos e demais legislação aplicável, toda a cópia, parcial ou total, deste documento, nos casos em que é legalmente admitida, deverá conter ou fazer-se acompanhar por este aviso.

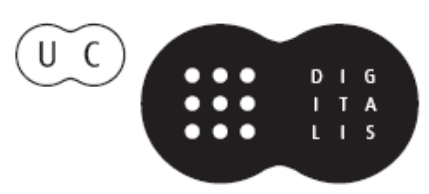


Rosa Maria Goulart

Universidade dos Açores / Centro de Literatura Portuguesa

\section{RUBEN A.: CONFIGURAÇÕES DE UM MAPA LITERÁRIO}

Muitas são as possibilidades de resposta quando nos interrogamos sobre as motivações, as finalidades e as configurações dos géneros autobiográficos, géneros que nas últimas décadas têm sido alvo de uma cuidadosa atenção dos estudiosos. E essa multiplicidade de respostas possíveis também se situa em dois planos distintos: no do autor que escreve e no do leitor que lê. Tratando-se de um género literário já conhecedor de uma razoável codificação e alvo de substancial bibliografia crítica, não nos deteremos em aspectos teóricos consabidos, embora não consensuais. A atestá-lo, estão as questões respeitantes à relação entre real e ficção; à co-referencialidade autor/narrador/personagem ou à alteridade daquele que se escreve; à literariedade ou à ausência dela; à suposta autenticidade do «eu» que se narra ou à sua inarredável inautenticidade; à interrogação sobre se o «eu profundo» do escritor se dá melhor a ver na ficção ou na autobiografia; etc.

Se Montaigne, nos seus ensaios de pendor autobiográfico, declarava que era a si próprio que pintava ("c'est moi que je peins»), não faltam, por outro lado, autores de "escritas do eu» a sublinhar a curta (ou nula) distância entre ficção e autobiografia. Não se trata exatamente, ou apenas, da constatação de que o «eu é um outro» (Rimbaud), mas ainda do facto de os filtros da memória, geralmente reconhecidos como factor decisivo na escrita da autobiografia, não constituírem garantia de uma estrita fidelidade ao real vivido.

O escritor José Manuel Caballero Bonald, com base na sua obra ficcional, analisa a relação entre autobiografia e ficção, reconhecendo que a fronteira entre elas é muito ténue e muito incerta. A razão é que, para ele, a ficção mais não é do que a realidade que o novelista reconstrói à sua maneira com "os escombros da memória», mas aquilo que a memória transporta não traz necessariamente o 
selo do real, pois a marca do irreal pode muito naturalmente incorporar-se ao próprio real vivido. A sua realidade é fruto da sua experiência, mas, alega, essa experiência pode tornar-se às vezes muito irreal: "A medida que envejezco, las cosas se me vuelven más irreales; las ideas tienden a irse desfigurando, disgregando el algún distrito de la memoria. Hasta las mentiras, las infracciones de la lógica, los irracionalismos de fondo, son variantes operativas de esa voluble y múltiple idea sobre la realidad. O sea, que la frontera entre la autobiografía y la ficción resulta siempre, a efectos literarios, ineludiblemente incierta» ${ }^{1}$.

À pergunta sobre que lugar ocupa Ruben A., autor tão atraído pelo registo autobiográfico, no meio de tais questões, acorre logo como resposta a epígrafe de Henry Miller colocada em O mundo à minha procura, que será tomado como objeto desta leitura ("Autobiography is the purest romance. Fiction is always closer to reality than facts), complementada com as outras considerações que o autor vai fazendo no prefácio dirigido ao leitor.

Pese embora o, não raro confessado, intuito de autognose que normalmente o autobiógrafo se propõe, não será ilegítimo pensar que a vontade de relatar a vida pessoal transporta, da parte quem o faz, um desejo de se mostrar com algum interesse - quem sabe se mesmo exemplaridade - para os outros. Na hipótese contrária, será a de uma necessidade absoluta de "falar em voz alta", de si para si, mas necessitada, ainda assim, de uma exteriorização. Quanto a Ruben A., ele deixa claro, como muitos outros, que o seu objetivo é perscrutar o seu "eu» profundo (o "eu à procura de mim no grande teatro do mundo", como escreve no terceiro volume da autobiografia ${ }^{2}$, na obsessão de descobrir a sua condição de Homem com maiúscula; porém, mais adiante conceberá o seu labor literário, onde aquela obra se inclui, como um gesto altruísta em direção ao seu virtual leitor.

As convenções tacitamente aceites por quem se impõe a tarefa de contar a própria vida reclamam um pacto de leitura segundo o qual o leitor, por sua vez, as acolha e tente compreender, mediante o reconhecimento da codificação genológica que enforma o texto a ler. O mais interessante, porém, reside, a montante, no modo como o autobiógrafo se dá a ver, construindo em originalidade, com

\footnotetext{
1 José Manuel Caballero Bonald, "Autobiografía y ficción», in Manuela Ledesma Pedraz (ed.), Escritura autobiográfica y géneros literarios, Jaén, Universidad de Jaén, 1999, p. 127.

2 Ruben A., O mundo à minha procura, vol. III, Lisboa, Assírio \& Alvim, 1994, p. 126 [1ª ed.: Parceria A. M. Pereira, 1968].
} 
um património comum, o da língua materna e da tradição literária e cultural, a imagem artística de si mesmo.

Em Ruben A. a encenação retórica levada a cabo por este «narciso de tinta» (expressão metafórica já consagrada para dizer esta imagem do «eu» que contempla, enamorado de si, a própria imagem nas águas em que se mira) na perspetivação do seu mundo interior e no traçado da respetiva cartografia é para nós um dos aspetos verdadeiramente interessantes da autobiografia em questão. E a grande novidade: em vez de se colocar num centro irradiante, em movimento centrífugo do sujeito para o mundo, o autor como que se imobiliza existencialmente à espera de que o mundo venha ao seu encontro. Não significa isto passividade, mas uma espécie de aceitação consentida daquilo que, vindo do exterior, sobredetermina a personalidade de quem o recebe e, talvez ainda, a ideia de que seria preciso que o mundo entrasse nele - e, por inclusão, que o escritor se encontrasse a si mesmo - para só então partir à descoberta do mundo e dos outros: "Antes de me atirar a ver e analisar o que se passava, ali no átrio, fora, na rua, mais longe na cidade, eu teria de me ver em ação, movimentar-me, crescer em entusiasmo, não quebrar na primeira esquina. O mundo procurava-me. Era um mundo que me vivia dentro, imenso e fechado, impenetrável aos colóquios, um só diálogo de mim para mim»³.

Ruben A. continua precisando as razões do seu egocentrismo até chegar à denúncia de uma obsessão pessoal que será reiteradamente exposta ao longo do último volume, a da condição humana, muitas vezes repetida sob a forma de interrogação sobre o que é ser Homem, uma pesquisa que marcha em sentido contrário ao do gregarismo e da massificação, pelos quais manifesta particular aversão. Na sociedade do "homem-massa", sobre a qual impende ameaça de "naufrágio calamitoso", "apenas se hão de salvar», prediz, "os que pela porta do cavalo fugirem ao triturar das grandes coletividades humanas, ou os que por força invencível e instintiva se libertarem para uma nova categoria de homem, ou antes, para a sua verdadeira categoria de homem, de homem-pensamento, na linha direta de um Platão, de um Homero, de um Aristófanes, de um Plutarco» ${ }^{4}$.

3 Ruben A., O mundo à minha procura, vol. I, 2a ed., Lisboa, Assírio e Alvim, 1992, p. 113 [1 $1^{\text {a }}$ ed.: Livraria Portugal, Lisboa, 1966].

4 Idem, ibidem, p. 116. 
É ainda «O mundo à [sua] procura» naquele decisivo encontro com o Minho e que o autor regista no terceiro volume da autobiografia ${ }^{5}$. Esta mudança de espaço, responsável pelo «nascimento» do escritor e pela génese da escrita, representa um alargamento de horizontes (conquanto de um horizonte ainda limitado se trate) e bem assim das fronteiras do seu mundo interior: "O mundo rodava. No regresso a Viana, depois desta noite fora, no primeiro dia de uma excursão meramente académica, eu nascia escritor, a explosão fora tão forte que pedira a um dos meus colegas uma folha de papel para escrevinhar nem sei o quê, pintor à base de pincel, escultor no agarra de escopro e martelo» ${ }^{6}$.

Desta geografia sentimental ressalta um fenómeno curioso e desconcertante. O alvoroço lírico (mas lirismo aqui é mero equívoco), que refere repetidamente ao longo do primeiro volume, nasce em (e decorre de) situações de exacerbação sentimental que não passam disso mesmo. Trata-se de um aspeto que não nos passa desapercebido, porquanto se trata sempre de denunciar sentimentos exaltados que só ganham sentido pela idade de quem os experimenta e que são apenas «lirismo de juventude» ${ }^{7}$. E é quando ele se desprende deste lirismo juvenil e olha o mundo como adulto, ou seja, quando se sente escritor, que o autor passa a descrever liricamente, agora sem os nomear, fragmentos desse todo que constitui a matéria da sua autobiografia.

É também numa outra fase, de amadurecimento, e após a desilusão amorosa que acabava de sofrer, que a linguagem do Amor, sempre latente, se alarga a

5 Cf. O mundo à minha procura, vol. III, pp. 81-82: «Agora aparecia-me o Alto Minho, eldorado onde ancorava todo o bojo que não soçobrara na débacle sentimental. A terra, o mar, o rio, a montanha, as aldeias, o povo, a arte, um todo que me agarrou no imediato, no transe da paixão, debaixo ainda do estado de choque. Abria-se um mundo novo, cosmo-físico para onde eu podia olhar, onde podia mergulhar, penetrando na Natureza sem pedir licença. Às vezes, nos imprevistos da vida, nas esquinas da sorte, nós esbarramos com um habitat que está desde a criação do mundo à nossa espera. Ali, intacto, permanente, rico, silencioso. [...] E, na inconsciência do consciente, às vezes reparava no segundo de tempo em que teria de, um dia, comunicar a outros o choque brutal que estava recebendo. Eu seria o médio que coa, filtra, decanta, o que paira sem rumo na Natureza, fosse o reino do Amor, quer o próprio caudal do telúrico.»

6 Ibidem, p. 87.

7 De certo modo, o autor admiti-lo-ia, ao reconhecer a filiação camiliana da sua exaltação amorosa: "Só anos depois, quando o amor começou a desinteressar-se das paisagens, pude considerar indiferente a maravilha que se deparava a meus olhos. Então comecei a notar que o outro nervosismo rompia de dentro para fora, era lírico em si mesmo, romântico nos primeiros tempos de inconsciência, apaixonado às mais graves consequências, camiliano sem restrições, não fosse o cenário do meu sofrimento viver-se ali perto do Amor de Perdição, com as barcas fundeadas no Douro, os recados, o medo de emboscada e o sofrimento estreme de quem se entrega a um amor perdido desde a primeira hora." 
outras dimensões, ao amor pela Natureza, ao amor por Inglaterra como terra de liberdade e de cultura que lhe devolve o verdadeiro eu, liberto das peias de uma sociedade a seus olhos tacanha, invejosa e mesquinha. O mundo alarga-se, portanto, na direta proporção das experiências da personagem que nele vive e com ele mede forças. O Campo Alegre da infância, como força centrípeta que reúne o clã familiar, como que se basta a si próprio até à altura em que começa a desintegrar-se e a reclamar uma inevitável expropriação. Até determinada altura tinha para ele o tamanho do mundo, em que os limites de cada qual acabavam ali mesmo ("A casa do Campo Alegre era [...] um mundo em tamanho grande»vol. I, p. 80). Porém, a sede de vivência, de conhecimento, de apropriação de novas terras vai aumentando constantemente o seu raio de ação. Para este Rei das descobertas, conhecer mundos e viver novas experiências é descobrir o seu caminho marítimo para a Índia e "dilatar a [sua] fé e o [seu] império" - é deste modo figurado que se refere aos preparativos para a primeira viagem à Alemanha ${ }^{8}$.

Se o mundo exterior procura o sujeito que vive e escreve, também este se define pelos espaços que constrói para habitar bem como pelos sentidos que lhes estão associados neste extraordinário percurso de vida. Parece-nos mesmo que todos os espaços que nesta autobiografia vão sendo referidos, descritos e analisados, se erigem como «espaços para habitar». No princípio, era a infância e o Campo Alegre9; depois a adolescência, a juventude e o treino para adulto; Cascais, o Minho, Coimbra, Lisboa, a Inglaterra. E, pelo meio, recantos de um Portugal em beleza natural, como atestam magníficas descrições (aos já mencionados é de acrescentar a serra da Arrábida, onde se faz a experiência única da «beleza de cara voltada para nós» ${ }^{10}$ ), nascidas de uma percepção alheia à visão negativista donde o escritor observa o País na sua dimensão política e social.

8 O mundo à minha procura, vol. II, $2^{\mathrm{a}}$ ed., Lisboa, Assírio e Alvim, 1993, p. 36 [1 $1^{\mathrm{a}}$ ed.: Parceria A. M. Pereira, Lisboa, 1966].

9 Sobre as memórias de infância, relatadas no primeiro volume da autobiografia, escreveu Paula Morão, reconhecida especialista, entre nós, dos estudos sobre autobiografia. Cf. «Souvenirs d'Enfance. Quelques Exemples Portugais", in Paula Morão (org.), in ACT 8 - Autobiografia e AutoRepresentação, Lisboa, Edições Colibri, 2003, pp. 55-74.

10 Cf. vol. II, pp. 155-156: «Quem nunca viu os contrafortes da serra da Arrábida pelas sete da manhã numa calmaria de Verão, não sabe o que é a beleza de cara voltada para nós. [...] A majestade iguala-se à paisagem, o mar inunda-se de rio, Tróia surge, mapa antigo de cartografia mal marcada para a nossa orientação. É um naco de terra que cresce, faz entrar o ar pelas narinas de todos os mansos pretos da existência." 
E daquilo que poderia, a um olhar estranho, surgir como normal ou rotineiro, como foi essa visita à serra da Arrábida, faz Ruben A. um momento decisivo no traçado da sua geografia existencial e afetiva, a subida de «um degrau no palanque da vida» ${ }^{11}$.

Se o mundo procura um sujeito expresso na sua singularidade, como o autor faz questão de ir sublinhando, num confronto eu/outros que não raro soa a narcisismo ou imodéstia antes que o tenhamos verdadeiramente percebido, ele procura igualmente um escritor, na medida em que este irrompe como que por determinação dos habitats que lhe vão sendo oferecidos. Mas, a fazer-nos lembrar a sua prima Sophia, estas dádivas da arte são também conquistadas, havendo que estar atento para as não deixar escapar quando vêm ao encontro do escritor. Foi assim com Sophia; terá sido assim com Ruben A., que se sente depois na obrigação de retribuir com a sua prestação no mundo os dons recebidos. Parece-nos ver aqui uma evolução na posição do escritor que dantes havia confessado apenas se preocupar consigo próprio, como se lê no texto introdutório ao primeiro volume, e que parece não ser compaginável com esta disponibilidade agora manifestada no último de «servir aos outros aquilo que em abundância [lhe] fora oferecido (vol. III, p. 82).

Bastou-lhe a revelação do Alto Minho, que corresponde, como o escritor anota, a "um período fundamental do [seu] caminho", a suscitar-lhe tal projeto de vida, paralelo de uma nova vida a emergir em imaginação e a transformar-se em escrita. Neste aspeto, aquele novo espaço que vem ter com ele representa um marco miliário no desenho da sua cartografia de homem e de escritor. Não será, certamente, desadequada aquela metáfora de índole geográfica, de tal modo ela se adequa a este artista da palavra que, ainda longe de pensar que se renderia à arte que a tem como matéria-prima, elegia, de entre as disciplinas escolares, a relação geografia/ciências naturais na construção do seu reino (vol. I, pp. 74-75).

Não obstante o pacto de leitura normalmente aceite neste tipo de escrito, o sonho e a imaginação, como já sugeria José Manuel Caballero Bonald no texto acima referido, apresentam-se tão reais para o autor quanto o real externamente

11 "Nunca vira espectáculo assim. Mergulhava, atirava-me como botânico, catalogava as braçadas, envolvia as folhas [...]. Íamos por Tróia dentro rastejando pelas giestas marinhas e perdendo a vista lá para o sul, onde Sines marca ponto final numa meia laranja da costa. Subira um degrau no palanque da vida.» (vol. II, p. 154). 
comprovado e comprovável, e entram com igual peso e legitimidade na configuração do seu microcosmo. Revertido fisicamente aos limites de si próprio quando a doença o impediu de andar, compensou a disforia do seu estado com a jubilosa entrada no campo dos sonhos e da imaginação, a única forma de ganhar os poderes que a sua condição física lhe negava. Restava-lhe então, alega, misturar aquilo de que gostava com o sonho, empreender uma viagem interior, criar um mundo só para si, o que lhe dava uma extraordinária ideia de independência e o desejo de se "aumentar no palco imenso da imaginação", onde "tudo se visualizava como sendo [ele] o único ser da Criação» (vol. I, p. 182).

Segundo José Palla e Carmo, com o qual é fácil concordar, o real vem ao encontro do Ruben A. já feito literatura; portanto, artisticamente configurado, porque, escreve o crítico, o escritor já está possuído pelo «dom da literariedade, a qualidade de ver, viver e descrever a realidade literariamente, sem ter que depois a traduzir em termos literários, porque a colhia já nesses termos.» ${ }^{12}$ Não será esta uma prerrogativa exclusiva deste autor, antes uma atitude partilhável com tantos outros companheiros de ofício, mas não é isso que agora importa. Importa, sim, notar a peculiaridade deste caso nessa feliz, e tão original, aliança entre um especial modo de ver e uma originalíssima maneira de escrever.

É nessa linha que os espaços a que chamaríamos amigáveis são já por si decisivos na demarcação de um território afetivo e intelectual, às vezes desvendados por um olhar que os soletra vagarosamente ou os recebe como revelação; é o mundo a oferecer-se-lhe em novas perspetivas ("Mas o que me importa notar neste período fundamental do meu caminho, creio ser uma certeza das coisas, uma resposta das árvores, das fragas, dos Cristos, das panorâmicas». - vol. III, p. 82), um excesso a passar em testemunho aos outros. Trata-se, aliás, nesta passagem, de uma performatividade do dizer, que é já um fazer, porquanto a afirmação dessa intenção dadivosa constitui um ato de escrita que oferece de imediato o que promete, através da expressão artística dos lugares que o emocionaram e lhe deram uma sabedoria que não passara nas lições recebidas na escola.

$\mathrm{Na}$ sua viagem pelo mundo e simultaneamente de autodescoberta como escritor, coloca-se-lhe o problema que normalmente atinge os artistas do verbo,

12 José Palla e Carmo, "Posfácio" de Kaos, Lisboa, Imprensa Nacional-Casa da Moeda, 1981, p. 259. Sublinhado do autor. 
nomeadamente os mais exigentes e insatisfeitos: o da representação do real. No caso da autobiografia, como inclinar-se para um pacto referencial extraliterário, pretendendo um acordo tácito com o leitor que o leve a aceitar como verdadeiro o relato de uma vida e ao mesmo tempo defender que toda a autobiografia é a mais pura ficção e que o real não se deixa aprisionar nas palavras que pretendem dizê-lo? Esta não é também, sabe-se, uma originalidade de Ruben A. Originalidade é, sim, o seu modo de o dizer, nessa linguagem difícil de expressar o complexo, o profundo e o contraditório da literatura. Neste aspeto, o autor desconstruiu a língua materna para a refazer, para lhe incorporar novas conotações, seja, como já foi salientado por outros estudiosos da sua obra, pela reinvenção da língua e criação de neologismos, seja pela figuralidade do estilo, onde metáforas, antíteses, metonímias ou sinédoques são indicativas de novos modos de encarar o real que supostamente todos conhecemos.

Porque descrever é também, e antes de tudo, perceber é que tão diferentes nos surgem as descrições segundo são percebidas por Ruben A. adulto, que figura certos espaços já se reconhecendo escritor, ou por Ruben Andresen Leitão criança, que vê com os olhos da infância e da adolescência, ora inebriado por certas realidades ora ávido de um mundo por conhecer. Porém, em qualquer das circunstâncias, é sempre a mão transfiguradora da escrita a responsabilizar-se pelo resultado final e, como sempre acontece em tais circunstâncias, a desfigurar ou a refigurar aquilo que, sendo passado, já foi e jamais voltará a ser como dantes.

A descrição do Natal no Campo Alegre, com o respetivo tempo de preparação e o seu ritual próprio, familiar, social, aliança de divino e profano, de mistura da tradição nacional com a nórdica, por via da ascendência dinamarquesa, constitui, a meu ver, um dos momentos altos na construção dessa representação cartográfica que tem vindo a ser referida. Trata-se de espaços que convocam tempos e recordações ou de tempos que convocam espaços e recordações. Tempos como aqueles que se reportam à celebração festiva do sagrado, rituais da vida ordenada em função de uma data memorável e em que tudo tem hora e lugar certo. Poucos episódios narrativos têm, a meu ver, nesta autobiografia a força e a autonomia que este representa. Essa experiência da criança - primeiro impaciente e expectante e depois deslumbrada - dita das mais belas páginas desta autobiografia, e fica a contrastar com a visão trágica de uma outra experiência deveras marcante na infância, a do naufrágio que terá presenciado no Porto. 
Paralelo, e por contraste, fica, assim, o naufrágio a que assistiu e que é igualmente narrado em pormenor e com a força presentificante de um verdadeiro testemunho e de uma inapagável e dolorosa experiência. Este, ao invés daquele, é evento singular, choque inesperado e uma vez acontecido, pelo que a respetiva descrição contrasta, em todos os aspetos, com a tão esperada, e ciclicamente realizada segundo idêntico ritual, festa do Natal.

Coimbra, onde chega a contragosto para estudar na Universidade, é, também por si, e contra o por ele esperado, um lugar onde se processa mais uma etapa no seu conhecimento do mundo. É lugar de cultura, embora o espaço para esta haja sido disponibilizado não pela Academia, mas por amigos cultos, como Agostinho da Silva, Vieira de Almeida, Cinatti, António Seabra, ("que sabia o Eça de cor e salteado» - vol. II, p. 171), ávidos de leitura e de partilha de livros, que lhe aplanaram o caminho. Coimbra fizera o resto: fora escola de vida, lugar de afirmação de uma maturidade conquistada e de uma personalidade independente ${ }^{13}$.

Desnecessário se torna, por demais evidente, insistir na reviravolta operada na mudança para Inglaterra, sempre alvo de confronto, no seu cosmopolitismo, nos seus valores de cidadania e na sua cultura, com a pequenez e o pouco civismo da terra de origem. Olhando esta a partir daquela, Ruben A. coloca-se também em lugar de apelo ao empreendimento de uma viagem cultural que lhe proporciona um diálogo com os maiores, nomes cimeiros da literatura e da cultura além-fronteiras. Deste modo, os espaços geográficos se tornam cada vez mais espaços de discussão cultural, onde o escritor, o professor, o cidadão se vai definindo - agora, sim - em movimento centrífugo, onde a vida, a literatura, a cultura, os valores de cidadania, as preocupações de índole política se conjugam para dar a dimensão de um universo que, mesmo com o regresso a Portugal, jamais se reduzirá à exiguidade do espaço de onde partiu, reclamando, assim, uma nova cartografia.

Essa etapa final, em cultura e maturidade assumida, chama, como não poderia fazê-lo anteriormente, em fecundo diálogo intercultural e interartístico, figuras notáveis, escritores como ele ou cultores de outras artes, da escultura

13 Cf. vol. II, p. 195: "Quem não esteve em Coimbra não percebe o que Coimbra representa na formação do indivíduo que passa a adulto. Carta de alforria, sebenta suja, mas livre leitura e livre discussão. Ali tem de se aguentar firme. Não há as saias da titi, nem a bolsa do paizinho a cobrir dívidas.» 
(António Duarte, depois em Inglaterra Henry Moore, Barbara Hepworth e L. Underwood) ou da pintura (Vieira da Silva), as quais ficam, assim, a constituir também marcos miliários do seu roteiro de homem e de artista. Em Portugal deixam-lhe marca indelével a força da poesia de Miguel Torga, "artista que nobilitava a palavra [...], genuíno na sua panorâmica telúrica e vegetal» (vol. III, p. 241), o "poeta Pedro" (Pedro Homem de Mello) com quem fez amizade no Porto, e vários outros.

Os "poetas da [sua] terra, os únicos proprietários de uma parte segura do mundo" (vol. III, p. 251), esses que ele ensinava em terra alheia, conferem nova dimensão aos espaços que, segundo cada etapa de vida, redimensiona para neles melhor habitar, agora que no estrangeiro ele «defendia a grandeza dos que eram grandes.» (vol. III, p. 256) e que muitas vezes a Pátria não reconhecia. Assim, o espaço de "emigração", que representava um bem colocado posto de vigia para observar as misérias nacionais, servia do mesmo modo para, à distância, valorizar e enaltecer a grandeza dos que nela ficaram ou que, já partidos deste mundo, merecem ser lembrados, estudados, dados a ler.

Em Inglaterra faz conviver escultura e teatro, revifica Gil Vicente no palco, encena "Mar", de Miguel Torga, reconhece-se, "homem do palco", onde, por sua intervenção, os textos ganham vida e as personagens um corpo. É ainda a escultura, arte onde as formas ganham relevo, que se habituou a admirar com António Duarte, Henry Moore, Barbara Hepworth e L. Underwood já referidos, a fornecer-lhe a motivação para a conversão metafórica em linguagem teatral: «Eu lia nas esculturas um espaço aberto que pertence à prosa, um palco, um drama a ser representado, e ouvia um silêncio majestático, imperturbável, vozes que se cruzavam, discerniam à medida que o confuso do barro se ia esclarecendo na imagem definida.» (vol. II, p. 168).

"Livre-pensador de estilo», assim ele gostava de ser, o que já foi sublinhado por vários críticos, entre eles José Carlos Seabra Pereira, que acrescenta ser a perseguida "emancipação da forma, do estilo e da linguagem» "emancipação pela forma, pelo estilo e pela linguagem»" "Livre-pensador de estilo», mas também, poder-se-á acrescentar, «livre-pensador» do mundo, de Portugal, de si próprio.

14 José Carlos Seabra Pereira, "Ruben A.: para animar o real", in AA. VV., O mundo à minha procura: Ruben A. trinta anos depois, Coimbra, Imprensa da Universidade de Coimbra, 2006, p. 19. 
Se, para este "narrador do seu País e narrador da sua Alma» (nas palavras certeiras de Marcelo Rebelo de Sousa ${ }^{15}$ ), a literatura é a sua «forma de viver todos os dias", a escrita autobiográfica é, por sua vez, mais do que mera escrita da vida, é vida da escrita e teatralização, palco onde o autor, na sequência da sua paixão pelo teatro, vendo-se e construindo-se personagem em representação (que é lugar propício à pública exibição dos seus vários «eus»), encena a própria existência. Diz-nos isso mesmo a recorrência de vocábulos pertencentes ao campo semântico da dramaturgia ("cenário», "palco", cena», "papel», "personagem»).

Esta escrita autobiográfica é, enfim, o lugar onde a palavra inquieta do autobiógrafo interroga o mundo e a existência, cruzamento desse «triálogo» entre Deus, a Morte e o Amor, poderosas entidades abstratas de essência indefinível ("Deus é, a Morte é, o Amor é - (vol. III, p. 247) que, segundo ele, dominam o universo e, por inclusão, diremos nós, o próprio microcosmo do escritor Ruben A. Por tudo isto, nos é a leitura da sua obra tão apelativa e tão sedutora.

15 Cf. «O nosso Ruben A.» (Prefácio de Páginas (VI), Lisboa, Assírio \& Alvim, 2001 [1ªed.: 1970]. 


\section{BIBLIOGRAFIA}

RUBEN A. (1992-1994), O Mundo à minha Procura, 3 vols., Lisboa, $2^{\text {a }}$ ed., Lisboa, Assírio \& Alvim, [1ª ed.: Parceria A. M. Pereira, Lisboa, 1966-1968].

CABALLERO BONALD (1999), José Manuel, "Autobiografía y ficción», in Manuela Ledesma Pedraz (ed.), Escritura autobiográfica y géneros literários, Jaén, Uiversidade de Jaén, p. 127.

MATHIAS, Marcello Duarte (2001), "O mundo à minha procura, ou Ruben A. à procura do seu mundo"; "Autobiografias e diários", in A Memória dos Outros, Lisboa, Gótica, pp. 66-72 e 163-193, respectivamente.

OLIVEIRA, Fernando Matos (2006), "Uma "sensação estranha de realidade: estética e diarística em Ruben A."”, in AA. VV., O mundo à minha procura: Ruben A. trinta anos depois, Coimbra, Imprensa da Universidade de Coimbra, pp. 55-62.

PEREIRA, José Carlos Seabra (2006), «Ruben A.: para animar o real», in AA. VV., O mundo à minha procura: Ruben A. trinta anos depois, Coimbra, Imprensa da Universidade de Coimbra, pp. 17-29.

ROCHA, Clara Crabbé (1992), Máscaras de Narciso. Estudos sobre a Literatura Autobiográfica em Portugal, Coimbra, Almedina.

SOUSA, Marcelo Rebelo (2001), "O nosso Ruben A.», prefácio de Páginas (VI), Lisboa, Assírio \& Alvim [1ªed.: 1970], pp. 9-13. 